DOT/FAA/AM-14/11

Office of Aerospace Medicine

Washington, DC 20591

\title{
Tricyclic Antidepressants Found in Pilots Fatally Injured in Civil Aviation Accidents
}

Zeki Dulkadir

Gülhane Military Medical Academy

Department of Aerospace Medicine

Eskisehir 26020, Turkey

Arvind K. Chaturvedi

Kristi J. Craft

Jeffery S. Hickerson

Kacey D. Cliburn

Civil Aerospace Medical Institute

Federal Aviation Administration

Oklahoma City, OK 73125

November 2014

Final Report 


\section{NOTICE}

This document is disseminated under the sponsorship of the U.S. Department of Transportation in the interest of information exchange. The United States Government assumes no liability for the contents thereof.

This publication and all Office of Aerospace Medicine technical reports are available in full-text from the Federal Aviation Administration website. 
Technical Report Documentation Page

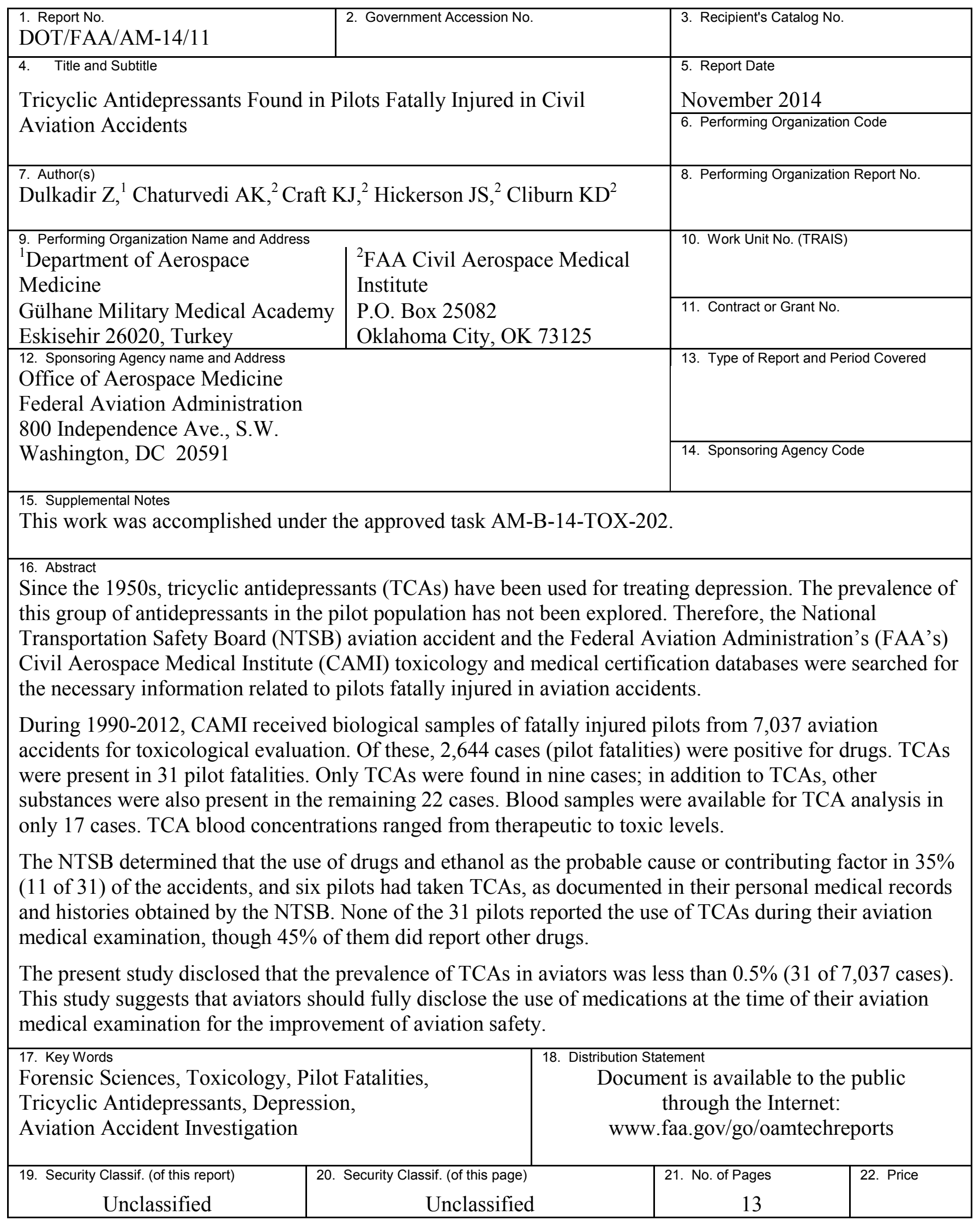

Form DOT F 1700.7 (8-72)

Reproduction of completed page authorized 



\section{ACKNOWLEDGMENT}

The Government of Turkey is acknowledged for allowing the participation of Dr. Zeki Dulkadir in the Federal Aviation Administration International Exchange Visitor Program at the FAA Civil Aerospace Medical Institute, Oklahoma City, Oklahoma. 



\section{Contents}

\section{Tricyclic Antidepressants Found in Pilots Fatally Injured in Civil Aviation Accidents}

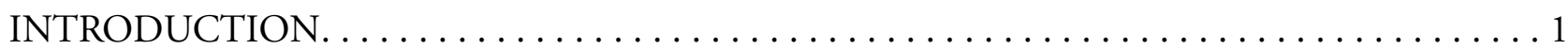

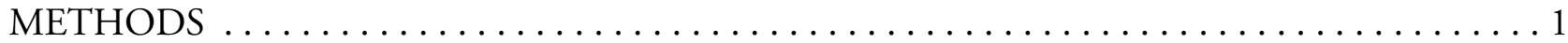

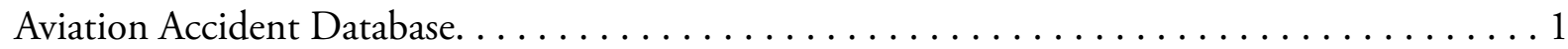

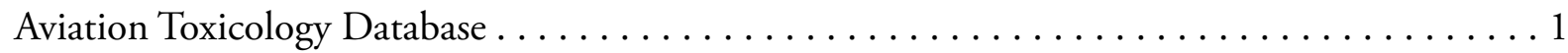

Pilot Fatality Biological Specimens $\ldots \ldots \ldots \ldots \ldots \ldots \ldots \ldots \ldots \ldots \ldots \ldots \ldots \ldots$

Pilot Fatality Case Number Assignment $\ldots \ldots \ldots \ldots \ldots \ldots \ldots \ldots \ldots \ldots \ldots \ldots \ldots$

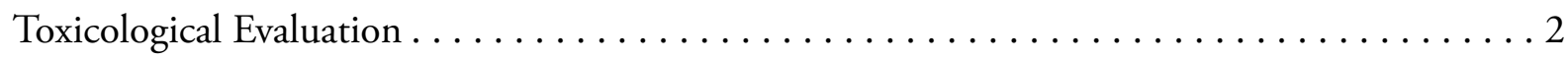

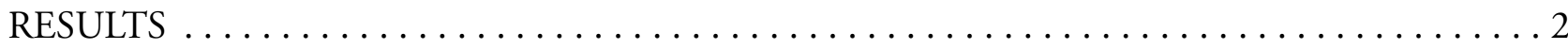

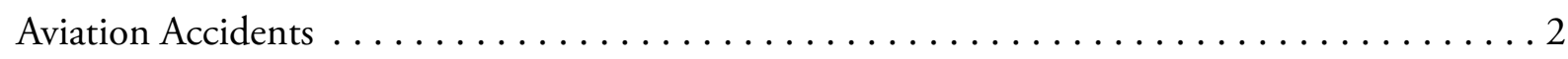

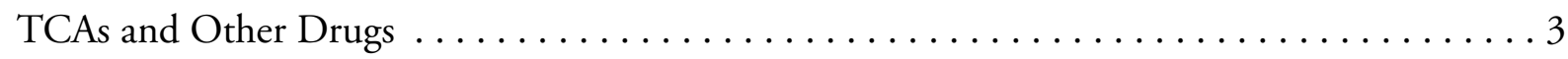

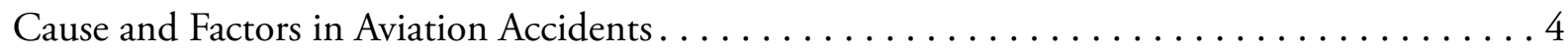

Demographic Elements and Flying/Medical Certificates $\ldots \ldots \ldots \ldots \ldots \ldots \ldots \ldots \ldots$

Aeromedical History . . . . . . . . . . . . . . . . . . . . . 6

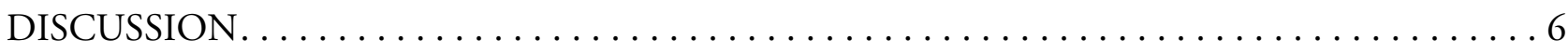

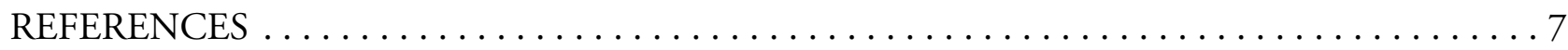





\section{Tricyclic Antidepressants Found in Pilots Fatally Injured in Civil Aviation Accidents}

\section{INTRODUCTION}

Tricyclic antidepressants (TCAs) are a group of drugs consisting of three rings in their chemical structure and considered first-generation antidepressants (23). Since the 1950s, TCAs have been clinically used to treat depression (4). Currently, 10 drugs pharmacologically fall under the category of TCAs (23). The names of these TCAs are amitriptyline, amoxapine, clomipramine, desipramine, doxepin, imipramine, maprotiline, nortriptyline, protriptyline, and trimipramine. Because of the adverse effects - for example, orthostatic hypotension, sedation, dry mouth, tachycardia, arrhythmias, constipation, blurred vision, weight gain, and lower seizure threshold - exhibited by TCAs $(21,23)$, these drugs are not favored as a first-line treatment option for depression.

Although TCAs are still commercially available, new generation antidepressants such as selective serotonin reuptake inhibitors (SSRIs) have been developed and are preferred medications over TCAs for treating depression (23). In a broader sense, the use of antidepressant drugs by aviators is not permitted in the United States (15). Since TCAs are antidepressants, this group of medications is also not approvable for aviators. However, SSRIs are considered for approval on a case-by-case basis to use under certain medical situations in the United States and other countries $(15,28)$. Although epidemiological aspects of the presence of SSRIs in civil aviation accident pilot fatalities has been evaluated $(2,27)$, no such evaluation has been made for TCAs.

Therefore, a study examining the prevalence of TCAs in 7,037 pilots fatally injured in civil aviation accidents was performed. This study entailed the search of aviation accident, toxicology, and medical certification databases to extract applicable information. This information consisted of the types and concentrations of TCAs found in the pilots, their flying and medical certificate categories, and their aeromedical histories. Additionally, the cause and factors leading to the aviation accidents were evaluated. Results of the study might be helpful to formulate aeromedical policies regarding the use of antidepressants by aviators.

\section{METHODS}

\section{Aviation Accident Database}

The National Transportation Safety Board (NTSB) aviation accident database was searched to find the number of fatal aviation accidents that occurred during the 1990-2012 period (22). This 23-yr period is consistent with the toxicology database maintained since 1990 at the Federal Aviation Administration's (FAA's) Civil Aerospace Medical Institute (CAMI) in Oklahoma City, OK. The categories of flight operations and the cause and factors in TCA-associated accidents were retrieved from the NTSB database as well. Any information pertaining to medication usage, medical conditions, or medical histories of the TCA-involved pilots, mentioned in the narratives of the NTSB accident investigation reports, was carefully evaluated and incorporated in the study.

\section{Aviation Toxicology Database}

Toxicological evaluations of the biological samples collected from the pilots fatally injured in aircraft accidents are stored In the aforementioned CAMI toxicology database. Additionally, other information related to the aviation accidents and the pilots is kept in this databank. Some of the fields of this toxicology database, such as aircraft number and accident narrative summaries, have links with those of the NTSB database (22). Flying and medical certificate categories of aviators obtained from the FAA Multi-System Access Tool database (19) and the CAMI Document Imaging and Workflow System (DIWS) $(18,20)$ are part of the CAMI toxicology databank. The DIWS was directly examined for extracting information pertaining to the relevant demographic elements and medical histories of the TCA-involved pilots.

The CAMI toxicology database was explored to find the number of aviation accidents and associated pilot fatalities from which CAMI received postmortem biological samples during the period of 1990-2012. This search also encompassed the number of pilot fatalities wherein drugs, including TCAs, were found to be present in the submitted postmortem biological samples.

\section{Pilot Fatality Biological Specimens}

The NTSB is responsible for investigating all U.S. civilian aircraft accidents. During the investigation of civil aviation accidents occurring within the jurisdiction of the United States, autopsied biological samples-blood, urine, vitreous fluid, spinal fluid, brain, lung, heart, liver, kidney, and/or other sample types - collected from pilots are submitted to CAMI for toxicological evaluation $(1,5,10)$. The submission of the specimens is authorized by the NTSB and coordinated through the FAA's Office of Accident Investigation and Prevention. The collected samples are shipped to CAMI in a special evidence container known as "TOX-BOX" (10).

\section{Pilot Fatality Case Number Assignment}

A specific CAMI case number is assigned to each pilot fatality from which the biological samples are collected and submitted to CAMI for analytical toxicology. Therefore, a particular fatality is referred to as a particular case. Only pilots are included in the present study. Since this study included accidents with only one pilot in command per aircraft, the number of pilots was equivalent to the number of aviation accidents. With an exception of a mid-air collision accident involving two aircraft, the accident was counted as one by the NTSB, but the pilots numbered two. 
In the present study, "case," "fatality," "pilot," "aviator," and "accident" are interchangeably used when and where necessary and appropriate.

\section{Toxicological Evaluation}

The CAMI toxicology laboratory's standard procedure is to use various techniques to analyze submitted biological samples for the presence of combustion gases (carbon monoxide and hydrogen cyanide), ethanol and other volatiles, and drugs $(5,6,10)$. The drugs include a wide range of nonprescription, prescription, and illicit drugs. The toxicological analysis has two components, preliminary (screening) and confirmatory/quantitative. Samples positive in the preliminary analysis are considered presumptive positives. New aliquots of such positive case samples are accessioned and further analyzed for confirmation/quantitation. These analyses are dependent upon the availability of specimen types, amounts, and physical conditions. Additionally, chemical characteristics of analytes and the sensitivity and specificity of analytical methods employed are critical elements of the analyses.

\section{RESULTS}

\section{Aviation Accidents}

During 1990-2012, the NTSB investigated 8,420 fatal aviation accidents, and CAMI received biological samples from 7,274 accidents. Of the 7,274 accidents, there were 7,037 accidents wherein pilots were fatally injured. The toxicological evaluation of these 7,037 cases revealed that 2,644 (38\%) were positive for drugs, including TCAs. Of the 2,644 cases, TCAs were determined to be present in 31 pilots. As is given in Table I, $29(94 \%)$ of the 31 antidepressant-related accidents were categorized as general aviation (Title 14 of the Code of Federal Regulations (CFR) Part 91) (13). The remaining two aircraft were operating under the categories of rotorcraft (14 CFR 133) and ultralight vehicle (14 CFR Part 103).

Table I. Operational Categories of Aircraft Involved in Fatal Civil Aviation Accidents and Associated Fatally Injured Pilots (1990-2012)

\begin{tabular}{|c|c|c|c|c|}
\hline \multirow{2}{*}{ Operational Categories ${ }^{*}$} & \multirow{2}{*}{$\begin{array}{c}\text { NTSB Database }{ }^{\dagger} \\
\text { Fatal Aviation } \\
\text { Accidents }\end{array}$} & \multicolumn{3}{|c|}{ CAMI Toxicology Database } \\
\hline & & $\begin{array}{l}\text { Fatal } \\
\text { Aviation } \\
\text { Accidents }\end{array}$ & $\begin{array}{l}\text { Fatally } \\
\text { Injured } \\
\text { Pilots }\end{array}$ & $\begin{array}{l}\text { TCA-Associated Fatally } \\
\text { Injured Pilots }\end{array}$ \\
\hline $\begin{array}{l}\text { General aviation } \\
\text { (14 CFR Part 91) }\end{array}$ & 7,541 & $6,258^{q}$ & 6,258 & 29 \\
\hline $\begin{array}{l}\text { Rotorcraft } \\
\text { (14 CFR Part 133) }\end{array}$ & 50 & 35 & 35 & 1 \\
\hline $\begin{array}{l}\text { Ultralight vehicle } \\
\text { (14 CFR Part 103) }\end{array}$ & 6 & 52 & 52 & 1 \\
\hline Total & 7,597 & 6,345 & 6,345 & 31 \\
\hline
\end{tabular}

* Code of Federal Regulations (CFR), Title 14 Parts (13). Only operations conducted under Parts 91, 133, and 103 were included herein because they were associated with accidents where TCAs were found to be present in the pilot fatalities.

"Unregistered aircraft, such as amateur-built ultralight vehicles, may not be included in these NTSB fatal accidents.

${ }^{*}$ Includes fatal accidents of registered and unregistered aircraft from which postmortem biological samples were submitted for toxicological evaluation. An example of unregistered aircraft could be amateur-built ultralight vehicles.

${ }^{\S}$ Translates into the equivalent number of aviation accidents, since there will be only one pilot per aircraft.

${ }^{\pi}$ One accident was a mid-air collision involving two aircraft, and that accident was counted twice by CAMI. 


\section{TCAs and Other Drugs}

The TCAs found in the 31 fatally injured pilots were imipramine, desipramine, amitriptyline, nortriptyline, doxepin/ nordoxepin, and clomipramine (Table II). There were 17 cases where blood samples were available to quantitate TCA. The blood concentrations of TCAs found in the pilots are given in Table III. The presence of TCAs in other sample types - heart, kidney, liver, lung, spleen, and/or urine — was also confirmed by performing either qualitative or semi-quantitative analysis. Only blood quantitative values of TCAs are incorporated in the table, since non-blood analysis results were qualitative or semi-quantitative in nature. Quantitative values in a non-blood biological sample cannot be realistically used to correlate with the degree of toxicity caused by a drug. As given in Table II, nine of the 31 pilots had only TCAs and/or their metabolites, whereas the remaining 22 pilots also had other substances in their body. The other substances were analgesics/narcotic analgesics (acetaminophen, dihydrocodeine, hydrocodone, hydromorphone, morphine,

Table II. TCAs Found in Civil Aviation Accident Pilot Fatalities

\begin{tabular}{|c|c|c|}
\hline \multirow{2}{*}{ TCAs } & \multicolumn{2}{|c|}{ Fatally Injured Pilots } \\
\hline & Without Other Substance(s) & With Other Substance(s) \\
\hline Imipramine/desipramine & $3^{\dagger}$ & 6 \\
\hline Desipramine & - & 4 \\
\hline Amitriptyline/nortriptyline & 3 & 8 \\
\hline Nortriptyline & - & 3 \\
\hline Doxepin/nordoxepin & 2 & 1 \\
\hline Clomipramine & 1 & - \\
\hline Total & 9 & 22 \\
\hline
\end{tabular}

Table III. Blood Concentrations (ng $\mathrm{ml}^{-1}$ ) of TCAs in Pilots Fatally Injured in Civil Aviation Accidents

\begin{tabular}{lcc}
\multicolumn{1}{c}{ TCAs } & $\begin{array}{c}\text { Without Other } \\
\text { Substance }\end{array}$ & $\begin{array}{c}\text { With Other } \\
\text { Substance(s) }\end{array}$ \\
\hline Imipramine; desipramine & - & $99-119^{\dagger} ; 96-6,510^{\dagger}$ \\
Desipramine & 161 & - \\
Amitriptyline; nortriptyline & $28 \& 74 ; 29 \& 120^{*}$ & $23-374^{\pi} ; 44-546^{\natural}$ \\
Nortriptyline & - & 4,226 \\
Doxepin; nordoxepin & - & $354 ; 139$ \\
Clomipramine & 80 & - \\
\hline
\end{tabular}

\footnotetext{
*Includes other drugs and ethanol.

${ }^{\dagger}$ Total four cases, but one case had only desipramine value.

*Total two cases.

" Total seven cases, but one case had only nortriptyline value.
} 
oxycodone, propoxyphene/norpropoxyphene, salicylate, and tramadol), anticholinergic/ parasympatholytic agent (atropine), anticonvulsant (carbamazepine), antidepressants (fluoxetine/ norfluoxetine, bupropion, paroxetine, and venlafaxine/desmethylvenlafaxine), antihistaminics (diphenhydramine and doxylamine), anorectic medication (phentermine), antitussive drug (dextromethorphan), benzodiazepines (chlordiazepoxide, diazepam/nordiazepam, oxazepam, and temazepam), betablockers (atenolol and propranolol), calcium-channel blockers (verapamil/norverapamil and diltiazem), local anesthetic and antiarrhythmic drug (lidocaine), muscle relaxants (carisoprodol and cyclobenzaprine), tranquilizer (meprobamate), and thiazolidinedione (pioglitazone). Ethanol ( $\geq 40 \mathrm{mg} \cdot \mathrm{dl}^{-1}$ or $\left.\mathrm{mg} \cdot \mathrm{hg}^{-1}\right)$ was detected in two of the 31 cases.

\section{Cause and Factors in Aviation Accidents}

Based upon the NTSB determination, the use of drugs and ethanol was reported as a probable cause or contributing factor in 11 of the 31 TCA-associated accidents (Table IV, following page). In one of the 11 cases, only TCA was present; in the remaining 10 cases, other substances were also detected. The probable cause and contributing factor in the remaining 20 of the 31 TCA-associated accidents were determined to be other than the usage of foreign substances and/or medical conditions.

\section{Demographic Elements and Flying/Medical Certificates}

Of the 31 pilots, 29 (94\%) were male and two (6\%) female; their average age was $58 \mathrm{yr}$ (SD 14; range 37 to 81). Occupationally, five pilots were physicians, one manager, one electrical engineer, one homebuilder, one real-estate agent, one businessman, one aircraft mechanic, and one pilot. Occupations of the remaining 19 pilots were not known. The flying experience of 28 of the 31 pilots had a wide range of distribution from 84 to 20,000 total flight h (mean: 2,929; SD: 4,016). The flying hour was recorded as "zero" for one pilot, and two did not have any medical record in the DIWS. The time period between the last medical examination and the accident date ranged from two to 59 months (mean: 19; SD: $15 ; N=28$ ). One fatally injured pilot was excluded from the calculation of the mean because the pilot's medical examination was performed approximately $20 \mathrm{yr}$ ago. This aviator was flying under the sport pilot category thus, was not required to hold a medical certificate. No medical records were available for the remaining two pilots.

Figure1 depicts the flying certificate categories of the aviators: one student, three airline transport, 10 commercial, and 16 private pilots. One pilot did not have any flying certificate. Two aviators held first-class, seven second-class, and 16 third-class medical certificates. The rest of the six pilots did not have medical certificates; one was flying under the sport pilot category.

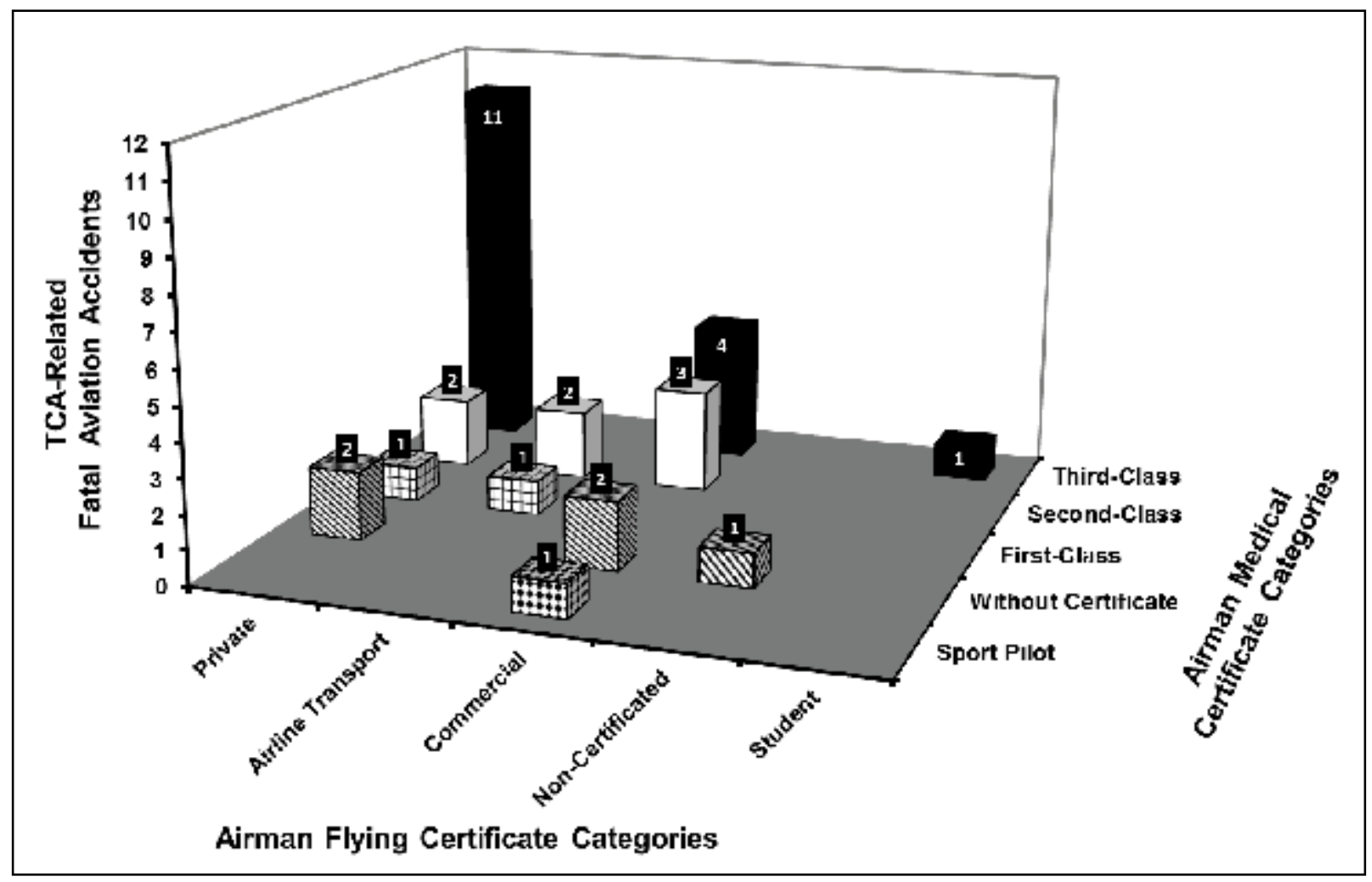

Figure 1. TCA-related fatal aviation accidents with respect to airman flying certificate categories and associated medical certificates 


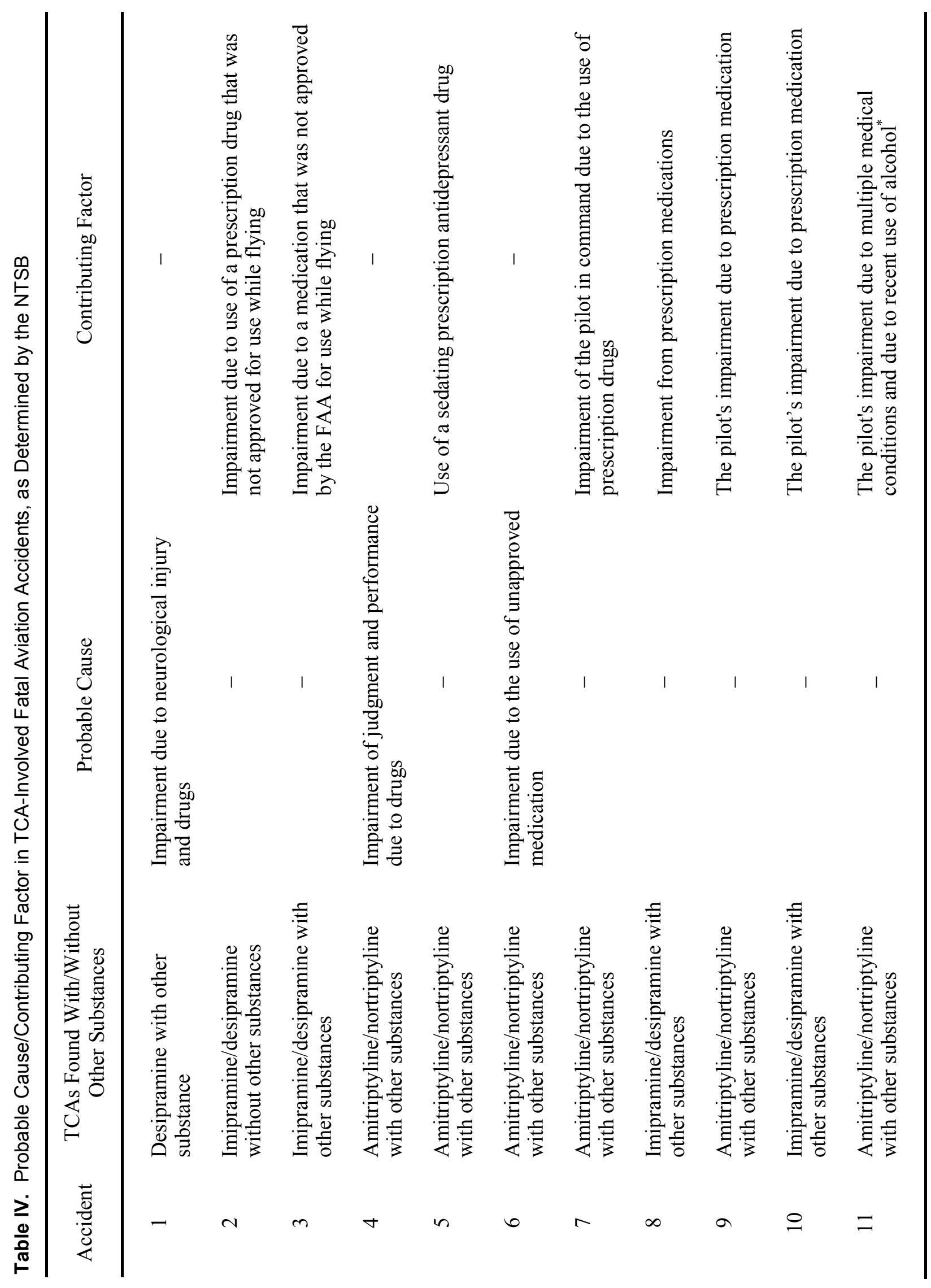




\section{Aeromedical History}

Per CAMI aeromedical records, none of the 31 pilots reported TCA usage and related medical conditions during their medical examination. However, a total of 14 of the 31 aviators reported the use of other medical drugs during the examination. The reported drugs were acetylsalicylic acid, atorvastatin, cisapride, enalapril, esomeprazole, famotidine, guaifenesin, ibuprofen, meloxicam, probenecid, simvastatin, sulfasalazine, tamsulosin, and terazosin. During the medical evaluation of one pilot, a general denial decision was made due to the aviator's disqualifying medical condition, which warranted the use of desipramine and diazepam. In another case, the pilot was informed that he did not meet medical standards for certification because of his use of amitriptyline. Later, upon the notification from the pilot and his aviation medical examiner that the aviator was no longer using this TCA, a medical certificate with the authorization of special issuance was granted. Remarkably, at the time of the medical examination, the pilot informed his medical examiner that he was not taking any medication, but amitriptyline was detected in his postmortem samples.

According to the narratives of the NTSB accident investigation reports, six of the 31 antidepressant-involved fatally injured pilots had a history of the use of a TCA. This conclusion was based upon the personal medical records and/or medical history of the pilots obtained by the NTSB during the accident investigation. Of these six pilots (cases), TCAs were prescribed for depression in three cases (one amitriptyline, one nortriptyline, and one imipramine), for pain in two cases (one imipramine and one amitriptyline), and for chronic insomnia in one case (amitriptyline). Notably, one of the three aviators with depression was a physician and was prescribed imipramine by his wife, who was also a physician. According to her, the pilot had seen a psychologist and was taking this drug for approximately $10 \mathrm{yr}$.

\section{DISCUSSION}

The number of aviation accidents from which biological samples were received at CAMI during the 23-yr period (1990-2012) was $86 \%$ of the fatal aviation accidents investigated by the NTSB for the period. This percentage is comparable to the values, $93 \%$ and $80 \%$, reported in earlier studies $(7,10)$. The difference between the NTSB $(8,420)$ and CAMI $(7,274)$ accident numbers might be because the NTSB may or may not investigate accidents involving unregistered aircraft. Additionally, the pilot may not have been fatally injured in some of those accidents. There might have been fatally injured copilots and/ or passengers in such accidents, thus they were also included in the NTSB aviation accident databank number.

However, aviation accidents from which biological samples were submitted to CAMI may include registered, as well as unregistered aircraft accidents, and only those accidents where pilots were fatally injured were incorporated in the present study; thus, fatally injured copilots and passengers were not part of the study. Other reasons for not receiving aviation accident postmortem samples could be un-recoverability of pilot remains from the accident scenes, religious beliefs of the pilot's family regarding autopsy and subsequent analysis, and the investigatorin-charge's decision not to send samples to CAMI (10). Most of the TCA-associated aviation accident flights (94\%) were operating under general aviation category (14 CFR Part 91) (13). The high percentage was consistent with the high percentages observed with the accidents investigated by the NTSB (99\%; 7,541) during 1990-2012 and with the fatal aviation accidents from which postmortem samples were received by CAMI (99\%; 6,258) during 1990-2012 (Table I). Similar high percentages of the Part 91 operational category have also been noted in previous studies $(2,8,9)$.

The TCA-involved accidents $(0.44 \%$; 31 of 7,037 pilot fatalities; 1990-2012) are considerably less compared to the SSRI-involved accidents (1.48\%; 61 of 4,128 pilot fatalities; 1990-2001) stated in an earlier study (2). An explanation for the fewer TCA-related accidents could be because TCAs are more toxic and less selective than SSRIs, thus TCAs are less preferred over SSRIs for treating depression (23). Under the aeromedical policy since 2010, SSRIs are being approved for pilots on a caseby-case basis in the United States $(11,14,15)$.

Of the 10 listed TCAs (23), only six TCAs were detected in the 31 cases. None of the cases had more than one TCA, other than TCA metabolites such as desipramine, nortriptyline, and nordoxepin. Desipramine and nortriptyline could be drugs, not metabolites, since they are also available as drugs in the market. The observed blood concentrations of the TCAs, in the absence of other substances, were within the therapeutic range $(26,29)$, but the TCA blood concentrations were in the therapeutic-totoxic range when other substances were present (Table III).

There were five such toxic range cases: one desipramine $(6,510$ $\left.\mathrm{ng} \cdot \mathrm{ml}^{-1}\right)$, three nortriptyline $\left(374,546\right.$, and 4,226 ng. $\left.\mathrm{ml}^{-1}\right)$, and one doxepin $\left(354 \mathrm{ng} \cdot \mathrm{ml}^{-1}\right)$. However, it must be emphasized that the concentrations found in the present study may not necessarily represent the true concentrations of the TCAs at the time of accidents. This emphasis is being made because (i) postmortem redistribution of the drugs does occur $(3,25)$ and (ii) pharmacokinetics, thus concentrations, of drugs do change when other substances are present in the body (24).

The substances, other than TCAs, found in the pilots were common medications used in the general population and are similar to those reported earlier with SSRIs (2). No controlled substances (12) were detected in the aviators wherein TCAs were detected. The presence of atropine, benzodiazepines, lidocaine, and narcotic analgesics in the pilots might have been associated with their administration to the accident victims by health care providers at accident scenes and/or at medical facilities. Other drugs could possibly have been obtained by the pilots through prescription or over-the-counter.

Investigations of all 31 accidents have been completed by the NTSB. Accordingly, the use of drugs and ethanol and/or a medical condition was reported as a probable cause or contributing factor in $35 \%$ ( 11 of 31 ) of the accidents. This percentage 
is basically similar to that reported earlier with SSRIs where the use of drugs or medical conditions were determined in 31\% (19 of 61) of the accidents (27).

The pilots wherein TCAs were detected (i) were of an average upper middle-age group (58 yr) and the majority (94\%) of them were male, (ii) basically represented a cross-section of varying professions, and (iii) had a wide range of flying experience. Although the TCA-related pilots were older than that reported in the U.S. Civil Airmen Statistics, wherein the average age of airmen is $45 \mathrm{yr}$ (17), the percentages of male and female pilots observed in the present study were similar to those reported in the airmen statistics (17). Most of the pilots held private pilot flying certificates and third-class medical certificates. Some pilots did not have flying or medical certificates. One aviator was a sport pilot without a medical certificate. For flying an aircraft as a sport pilot, an aviator must hold a medical certificate or a valid driver's license to exercise this privilege (16).

Although none of the 31 pilots reported TCA usage and associated medical conditions during their medical examinations, $45 \%$ did report other drugs that could be used without jeopardizing their qualification to obtain a medical certificate. It is clearly evident from the toxicological findings that, in spite of not mentioning TCAs during their aviation medical examinations, the personal medical records and/or medical history of the pilots directly obtained by the NTSB revealed the use of TCAs by six of the 31 fatally injured pilots. These pilots had been diagnosed with medical conditions that required taking TCAs. In fact, one pilot had taken a TCA for $10 \mathrm{yr}$, but the aviator never informed his aviation medical examiner. The evaluation of personal medical records and history for the purposes of accident investigations is an effective approach in deducing whether an aviator was taking an unreported or unauthorized medication.

Overall, the present study disclosed that the usage of TCAs in aviators is not prevalent in comparison to SSRIs. Although none of the pilots had reported TCAs at the time of their aviation medical examinations, these antidepressants were found in their body. The findings of this study suggest the necessity for aviators to fully disclose the medications that they are taking for the improvement of aviation safety.

\section{REFERENCES}

1. Aviation Safety Research Act of 1988: Public Law 100591 [H.R. 4686]. 100th U.S. Cong., 2nd Sess., 102 Stat. 3011; 03 November 1988.

2. Akin A, Chaturvedi AK. Selective serotonin reuptake inhibitors in pilot fatalities of civil aviation accidents, 1990-2001. Aviat Space Environ Med 2003; 74(11):1169-76.

3. Anderson WH, Prouty RW. Postmortem redistribution of drugs. In: Baselt RC, ed. Advances in analytical toxicology. vol 2. Chicago, IL: Year Book Medical Publishers, Inc.; 1989:70 -102.
4. Baselt RC, ed. Disposition of toxic drugs and chemicals in man. 8th ed. Foster City, CA: Biomedical Publications; 2008.

5. Chaturvedi AK. Aerospace toxicology: an overview. Washington, DC: Federal Aviation Administration, Office of Aerospace Medicine; 2009 Apr. Report No. DOT/FAA/AM-09/8.

6. Chaturvedi AK, Botch SR, Canfield DV, Forster EM. Vitreous fluid and/or urine glucose concentrations in 1335 civil aviation accident pilot fatalities. J Forensic Sci 2009; 54(3):715-20.

7. Chaturvedi AK, Botch SR, Ricaurte EM. Toxicological findings in 889 fatally injured obese pilots involved in aviation accidents. J Forensic Sci 2012; 57(2):420-6.

8. Chaturvedi AK, Craft KJ, Canfield DV, Whinnery JE. Toxicological findings from 1587 civil aviation accident pilot fatalities, 1999-2003. Aviat Space Environ Med 2005; 76(12):1145-50.

9. Chaturvedi AK, Craft KJ, Hickerson JS, Rogers PB, Soper JW. Toxicological findings in fatally injured pilots of 979 amateur-built aircraft accidents. Aviat Space Environ Med 2013; 84(2):134-41.

10. Chaturvedi AK, Smith DR, Soper JW, Canfield DV, Whinnery JE. Characteristics and toxicological processing of postmortem pilot specimens from fatal civil aviation accidents. Aviat Space Environ Med 2003; 74(3):252-9.

11. DeVoll J. FAA experience with neuropsychological testing for airmen with depression on SSRI medications. [Abstract.]. Aviat Space Environ Med 2013; 84(4):40910 .

12. e-CFR. Electronic Code of Federal Regulations (e-CFR), Title 21: Food and drugs, Chapter II: Drug Enforcement Administration, Department of Justice, Part 1308Schedules of controlled substances; Retrieved 10 July 2014 from http://ecfr.gpoaccess.gov/cgi/t/text/text-idx?c= ecfr\&sid=9043159b1a6ae49eea4d4bbd618d39e 5\&rgn= div5\&view=text\&node $=21: 9 \cdot 0 \cdot 1.1 .9 \& \mathrm{i}$

dno $=21 \# 21: 9 \cdot 0.1 \cdot 1 \cdot 9 \cdot 0.26$

13. e-CFR. Electronic Code of Federal Regulations (e-CFR), Title 14-Aeronautics and space, Chapter I-Federal Aviation Administration, Department of Transportation; Retrieved 02 May 2014 from http://www.ecfr.gov/cgibin/text-idx?SID=fcd1285bde7b014dcd7f0bcff0fba8c4 \&tpl=/ecfrbrowse/Title14/14tab_02.tpl

14. Federal Aviation Administration. Press release - FAA proposes new policy on antidepressants for pilots; Retrieved 09 July 2014 from http://www.faa.gov/news/ press_releases/news_story.cfm?newsId $=11293$. 
15. Federal Aviation Administration. Guide for aviation medical examiners; Retrieved 22 May 2014 from http:// www.faa.gov/go/ameguide

16. Federal Aviation Administration. Sport pilot and sport pilot flight instructor certification; Retrieved 16 July 2014 from http://www.faa.gov/licenses_certificates/ airmen_certification/sport_pilot/media/LSPBrochure.pdf

17. Federal Aviation Administration. U.S. civil airmen statistics; Retrieved 11 July 2014 from http://www.faa. gov/data_research/aviation_data_statistics/civil_airmen_ statistics/

18. Federal Aviation Administration. Medical Support System (Document Imaging \& Workflow System, DIWS); Retrieved 29 April 2014 from https://mss-diws. avs.faa.gov/webclient

19. Federal Aviation Administration. Multi-System Access Tool airman information; Retrieved 29 April 2014 from https://av-info.avs.faa.gov/MSAT/MSATDefault.aspx

20. Federal Aviation Administration. AAM-300-001 Aerospace Medical Certification Process; Retrieved 19 September 2014 from https://my.faa.gov/org/ linebusiness/avs/programs/qms/qms_homepages/aam/ qms_divisions/aam_300/procedures.html

21. Kerr GW, McGuffie AC, Wilkie S. Tricyclic antidepressant overdose: A review. Emerg Med J 2001; 18(4):236-41.

22. National Transportation Safety Board. Aviation accident database \& synopses; Retrieved 18 April 2014 from http://www.ntsb.gov/aviationquery/index.aspx
23. O’Donnell JM, Shelton RC. Drug therapy of depression and anxiety disorders. In: Brunton LL, Chabner BA, Knollmann BC, eds. Goodman \& Gilman's the pharmacological basis of therapeutics. 12th ed. New York, NY: McGraw-Hill; 2011:397-415.

24. Osterhoudt KC, Penning TM. Drug toxicity and poisoning. In: Brunton LL, Chabner BA, Knollmann BC, eds. Goodman \& Gilman's the pharmacological basis of therapeutics. 12th ed. New York, NY: McGrawHill; 2011:73-87.

25. Pounder DJ, Jones GR. Post-mortem drug redistribution--A toxicological nightmare. Forensic Sci Int 1990; 45(3):253-63.

26. Schulz M, Iwersen-Bergmann S, Andresen H, Schmoldt A. Therapeutic and toxic blood concentrations of nearly 1,000 drugs and other xenobiotics. Crit Care 2012; 16(4):R136.

27. Sen A, Akin A, Canfield DV, Chaturvedi AK. Medical histories of 61 aviation accident pilots with postmortem SSRI antidepressant residues. Aviat Space Environ Med 2007; 78(11):1055-9.

28. Vuorio A, Laukkala T, Navathe P. Major depression and fitness to fly by different aviation authorities. Aviat Space Environ Med 2012; 83(9):909-11.

29. Winek CL, Wahba WW, Winek CL, Jr., Balzer TW. Drug and chemical blood-level data 2001. Forensic Sci Int 2001; 122(2-3):107-23. 